\title{
Biomarkers of inflammation in infants with cystic fibrosis
}

\author{
Theresa A. Laguna ${ }^{1 *}$, Cynthia B. Williams', Myra G. Nunez', Cole Welchlin-Bradford', Catherine E. Moen', \\ Cavan S. Reilly ${ }^{2}$ and Chris H. Wendt ${ }^{3}$
}

\begin{abstract}
Background: There are urgent needs for clinically relevant biomarkers to identify children with cystic fibrosis (CF) at risk for more progressive lung disease and to serve as outcome measures for clinical trials. Our objective was to investigate three targeted biomarkers in a population of asymptomatic CF infants.

Methods: Urine, blood and lung function data were collected for 2 years from clinically stable infants diagnosed with CF by newborn screening. A subset of CF infants had bronchoscopy with lavage performed at 6 months and 1 year. Urine was collected quarterly from healthy control infants. Expectorated sputum and urine were collected quarterly for 2 years from clinically stable CF adults. Desmosine, club cell secretory protein (CCSP) and cathepsin B concentrations were measured and compared. Mixed effects models were used to identify associations between biomarker concentrations and clinical characteristics. Receiver operator characteristic curves were generated to investigate the sensitivity and specificity of the biomarkers.
\end{abstract}

Results: Urinary cathepsin B was significantly higher in CF infants compared to healthy infants $(p=0.005)$. CF infant airway and urinary cathepsin B concentrations were significantly lower compared to adult CF subjects $(p=0.002 \&$ $p=0.022$, respectively). CF infant airway CCSP was significantly higher than adult CF subjects $(p<0.001)$. There was a significant correlation between CF infant plasma CCSP and BALF CCSP $(p=0.046)$. BALF CCSP was negatively associated with IL-8 $(p=0.017)$. There was no correlation between biomarker concentration and $\mathrm{FEV}_{0.5}$.

Conclusions: Cathepsin B and CCSP show promise as biomarkers of inflammation in CF infants. Further study is needed.

Keywords: Inflammation, Lung function, Infection, Pediatrics, Bronchoalveolar lavage fluid

\section{Background}

Cystic fibrosis (CF) lung disease begins silently in infancy and is characterized by infection, chronic inflammation, bronchiectasis, progressive lung function decline and intermittent pulmonary exacerbations [1-5]. Early detection and treatment of pulmonary decline is key to optimal long-term outcome; however, physiologic measures of lung function and radiologic outcomes fail to capture the inflammation and infection that begins in infancy and is often silent in CF [6-8]. In addition, with the recent development of medications targeting the

\footnotetext{
* Correspondence: lagun005@umn.edu

Results have been previously presented as a poster presentation by Dr. Laguna at the North American Cystic Fibrosis Conference 2015 (Phoenix, AZ). ${ }^{1}$ Minnesota CF Center, Department of Pediatrics, University of Minnesota Masonic Children's Hospital, 420 Delaware St. SE; MMC-742, Minneapolis, MN 55455, USA

Full list of author information is available at the end of the article
}

genetic mutations in $\mathrm{CF}$, there is a need for outcome measures suitable for infants and young children for clinical trials. There are limited, non-invasive, objective tools available to help identify those CF infants at risk for a more rapidly progressive pulmonary course. This unmet need could be fulfilled by identifying biomarkers of lower airway inflammation and/or injury that are suitable both as "point-of-care" diagnostics and for monitoring longitudinal changes.

Neutrophilic inflammation, enzymatic protease activity and cytokine release are hallmarks of CF lung disease with the presence of neutrophil elastase (NE) in BALF known to be a risk factor for the development of bronchiectasis [9]. However, surveillance bronchoscopy with lavage is an invasive procedure that is not routinely performed in the United States, making the measurement of NE in young patients challenging. Biomarkers that 
reflect CF lung disease in easily obtained biological specimens are more feasible for application in both the clinical and research settings. Three biomarkers - desmosine, club cell secretory protein (CCSP) and cathepsin B have previously been associated with CF lung disease; however, their applicability to CF infants has not been investigated [10-18]. We have shown that sputum CCSP concentration was both higher in adults with CF in the outpatient setting compared to during a CF pulmonary exacerbation and negatively associated with sputum NE concentration [17]. CCSP is produced by bronchial epithelial cells and known to have anti-inflammatory properties and may reflect CF lung disease activity [17]. We have also shown that both sputum and urinary desmosine concentration decrease significantly during a CF pulmonary exacerbation $[11,12]$. Previous work in premature infants and animals has suggested CCSP, cathepsin B and desmosine may all play a role in the development of chronic lung disease [19-22]. Desmosine is a breakdown product of elastin and is widely described as a non-specific biomarker of lung injury. Cathepsin B is an elastolytic cysteine protease that is linked to remodeling of extracellular matrix, bacterial infection and biofilm formation in the CF airways, specifically involving Pseudomonas aeruginosa, a known pathogen in CF $[10,13-16]$. These three targeted biomarkers may provide an objective measure of the degree of inflammation or tissue destruction occurring in the lung, and if so, would be invaluable both for clinical management and as surrogate endpoints for clinical trials.

Our objective was to measure the concentration of desmosine, CCSP and cathepsin B during the first 2 years of life and correlate biomarker concentrations with markers of infection, inflammation and lung function. We also sought to compare biomarker concentrations measured in CF infants with those measured in a cohort of healthy infants and in an adult cohort of patients with $\mathrm{CF}$ with more established lung disease [17]. Some of the results of these studies have been previously reported in the form of an abstract [23].

\section{Methods}

\section{Study Design for Infant Study}

A single-center, two-year prospective cohort study of infants diagnosed with $\mathrm{CF}$ via newborn screening was performed. Infants were enrolled at their 3 month visit to the University of Minnesota (UMN) CF Clinic from 2009 to 2015. All infants with a confirmed diagnosis of CF [i.e. two known disease causing cystic fibrosis transmembrane conductance regulator (CFTR) mutations and/or a positive sweat chloride test by pilocarpine iontophoresis] were eligible to participate. Each subject had a blood sample taken and infant lung function testing (iPFT) performed every 6 months and provided a bag urine sample quarterly for 2 years. Under a separate study protocol, a subset of CF infants underwent a bronchoscopy with bronchoalveolar lavage following their iPFT at 6 months of age and 1 year. We collected demographic data and performed an upper airway nasopharyngeal (NP) culture quarterly at clinic visits. Healthy, control infants recruited from a local pediatric clinic provided only a bag urine sample quarterly for 2 years. Infants were recruited at outpatient well-child visits and were required to have no history of prematurity or known lung disease to participate. The UMN Institutional Review Board (IRB) approved study protocols and written informed consent was obtained from each of the subject's parents or legal guardians.

\section{Study design for adult CF study}

A single-center, two-year prospective cohort study of patients with CF during times of pulmonary exacerbation (hospitalization) and times of clinical stability (outpatient clinic visits) was performed. Subjects with a confirmed diagnosis of $\mathrm{CF}$ were enrolled upon admission for treatment of a pulmonary exacerbation from 2008 to 2011 [24]. For study purposes, a pulmonary exacerbation was defined as the need for hospitalization for intravenous (IV) antibiotics. Each subject provided an expectorated sputum and urine sample at up to three time points. Upon discharge, expectorated sputum and urine samples were collected quarterly at outpatient visits for 2 years. For the purposes of this study, only specimens collected during outpatient visits were analyzed. If a $\mathrm{CF}$ patient was on IV antibiotics or received a diagnosis of a $\mathrm{CF}$ pulmonary exacerbation at a clinic visit, samples were excluded from the analysis. The study protocol was approved by the UMN IRB and informed consent and/ or assent were obtained from each of the subjects and/ or their parents or guardians.

\section{Procedures \\ Infant lung function testing}

Using the Infant Plethysmograph (IPL) from nSpire Health, this procedure is attempted on CF infants at the Minnesota CF Center every 6 months for the first 2 years of life as standard-of-care. For the iPFT procedure, infants were sedated with oral chloral hydrate and oral hydroxyzine. We were unable to obtain iPFT data on the infants that were unable to sleep through the entire procedure. The forced expiratory volume in $0.5 \mathrm{~s}\left(\mathrm{FEV}_{0.5}\right)$ by the raised volume rapid thoracoabdominal compression technique (RVRTC) was collected [25-27].

\section{BALF specimen collection/processing}

As part of a separate, IRB-approved study protocol, bronchoscopy with lavage was performed on a small number of CF infants immediately following the iPFT procedure to take advantage of the already administered 
sedation. Two aliquots of $1 \mathrm{~mL} / \mathrm{kg}$ of sterile normal saline were instilled into the right middle lobe. All BALF was pooled and immediately placed on ice. One aliquot was sent to the UMN clinical laboratory for cell count and differential and the qualitative identification of respiratory pathogens by standard microbiological techniques [28-30]. The UMN Microbiology Laboratory does not quantify the amount of bacteria present on standard culture. The remaining BALF was centrifuged at $250 \times \mathrm{g}$ for $10 \mathrm{~min}$ at $4{ }^{\circ} \mathrm{C}$. The supernatant was transferred with a sterile pipette to a separate tube, protease inhibitors were added, and the mixture centrifuged at $4000 \times \mathrm{g}$ for $20 \mathrm{~min}$ at $4{ }^{\circ} \mathrm{C}$. The sample was stored at $-80{ }^{\circ} \mathrm{C}$ for future analysis. CCSP and cathepsin B concentration were measured in BALF as described below.

\section{NP specimen collection}

Nasopharyngeal specimens collected by inserting a sterile suction catheter through the nose followed by gentle suction are standard of care at the Pediatric UMN CF Center. The specimen was sent for the same qualitative identification of respiratory pathogens as per the BALF specimen.

\section{Sputum collection/processing}

Expectorated sputum from adults with CF was processed as previously described and frozen immediately after collection at $-80{ }^{\circ} \mathrm{C}$ prior to analysis [31]. CCSP and cathepsin $\mathrm{B}$ concentrations were measured in sputum as described below.

\section{Urine collection/processing}

A bag urine sample was collected from all infants and a clean catch specimen was collected from adult CF subjects. Urine was centrifuged at 4000RPM for $10 \mathrm{~min}$ and the supernatant was aliquoted and stored at $-80{ }^{\circ} \mathrm{C}$ for future analysis. Urine samples were shipped on dry ice for desmosine analysis. Cathepsin B concentration was also measured in urine as described below.

\section{Blood collection/processing}

A blood sample was collected from all CF subjects in standard BD vacutainer tubes and centrifuged at 4000 RPM for $10 \mathrm{~min}$. The resultant plasma and serum supernatants were aliquoted and stored at $-80{ }^{\circ} \mathrm{C}$ for future analysis.

\section{Laboratory assays \\ Biomarker assays}

CCSP concentration was measured in plasma, sputum and BALF supernatant treated with protease inhibitors using a human-specific competitive ELISA assay (Clarassance, Inc.; Rockville, MD, USA). The limit of detection (LOD) for this assay was $5 \mathrm{ng} / \mathrm{mL}$. Four parameter logistic curves were used that ranged from 5 to $500 \mathrm{ng} / \mathrm{mL}$. The intra-assay coefficient of variation (CV) was $<12 \%$ and the inter-assay $\mathrm{CV}$ was $<10 \%$. Specimens were run in duplicate and a human serum control was used to ensure reproducibility. Desmosine concentration was measured in infant urine using a liquid chromatography, mass spectrometry-based assay at the University of Dundee [32]. Cathepsin B concentration was measured in BALF and sputum supernatant treated with protease inhibitors and in urine using a competitive ELISA assay (R\&D Systems, Inc.; Minneapolis, MN, USA). The reported mean minimum detectable concentration for this assay was $0.016 \mathrm{ng} / \mathrm{mL}$. Four parameter logistic curves were used that ranged from 0 to $10 \mathrm{ng} / \mathrm{mL}$. The intra-assay CV was $<10 \%$ and the inter-assay CV was $<10 \%$.

\section{BALF analysis}

BALF NE activity was quantified by a spectrophotometric assay based on the hydrolysis of the specific substrate $\mathrm{MeO}$-suc-Ala-Ala-Pro-Ala-p-nitroanilide (Sigma Chemical Co.; St. Louis, MO). IL-8 was measured as a component of an eight-plex cytokine assay (EMD Millipore Corporation; Billerica, MA).

\section{Urine analysis}

Urinary creatinine and specific gravity were measured for normalization purposes [33].

\section{Statistical analysis}

Descriptive statistics include the mean and standard deviation or the median and range, where specified. Linear mixed effects models were used to model the logarithm of targeted biomarker levels that were longitudinally assessed with subject-specific, additive random effects. Analysis of urine samples controlled for creatinine and specific gravity by taking the log and including them as covariates. Sputum and BALF biomarker concentrations were not normalized prior to analysis. To test for an association between urinary cathepsin $\mathrm{B}$ levels and CF status, a model with the $\log$ of cathepsin B as the response variable and the $\log$ of specific gravity, the $\log$ of creatinine, age, CF status and the interaction between age and the indicator for CF status was fit. The test for an association between BALF CCSP and plasma CCSP was based on a model which had BALF CCSP as a response variable and included no other covariates (although the results were not sensitive to inclusion of gender and age). A similar analysis detected the association between CCSP and IL-8. Two sample t-tests were used to test for differences in biomarker concentration between infants and older subjects with CF [17]. Receiver operator characteristic (ROC) curves were generated to examine the sensitivity and specificity of the biomarkers. All calculations were conducted using $\mathrm{R}$ 
version 2.15 .2 and mixed effects models were fit using the lme function in the nlme package [34].

\section{Results}

\section{Study population}

Demographic data for the study population is presented in Table 1. The median $\mathrm{FEV}_{0.5} \%$ predicted (range) for those infants who received an iPFT $(n=21)$ was $96 \%$ predicted (range, 66-125\%). The predominant genotype of the infant CF population was F508del/F508del. Eleven

Table 1 Demographics of CF Infant Cohort, CF infants who received a bronchoscopy, Healthy Control Infants and Adult CF Subjects

\begin{tabular}{|c|c|c|}
\hline & Characteristic & Value \\
\hline \multirow[t]{11}{*}{ CF Infants (Total) } & Subjects & 33 \\
\hline & Female:Male & $20: 13$ \\
\hline & Age at enrollment (months) & $3.5(0.4-13.0)$ \\
\hline & Initial FEV 0.5 (\% predicted) & $96(66-125 \%)$ \\
\hline & \# urine samples collected & 130 \\
\hline & \# blood samples collected & 41 \\
\hline & \# iPFT procedures performed & 36 \\
\hline & P. aeruginosa positive during study & 5 \\
\hline & F508del/F508del & $19(58 \%)$ \\
\hline & F508del/other & $12(36 \%)$ \\
\hline & other/other & $2(6 \%)$ \\
\hline \multirow[t]{8}{*}{ CF Infants (BALF) } & Subjects & 8 \\
\hline & Female:Male & $6: 2$ \\
\hline & BALF Samples & 12 \\
\hline & Age at first BAL (months) & $6.1(5.7-6.5)$ \\
\hline & Age at second BAL (months) & $12.2(11.8-13.2)$ \\
\hline & FEV0.5 at first BAL (\% predicted) & $98(69-125 \%)$ \\
\hline & F508del/F508del & $7(88 \%)$ \\
\hline & F508del/G551D & $1(12 \%)$ \\
\hline \multirow[t]{4}{*}{ Healthy Infants } & Subjects & 40 \\
\hline & Female:Male & $20: 20$ \\
\hline & Age at enrollment (months) & $2.4(1.8-12.0)$ \\
\hline & \# urine samples collected & 90 \\
\hline \multirow[t]{10}{*}{ CF Adults } & Subjects & 36 \\
\hline & Female:Male & 19:17 \\
\hline & Age at enrollment (years) & $29.8(13.0-56.6)$ \\
\hline & FEV1 (\% predicted), clinic & $56(18-96 \%)$ \\
\hline & \# urine samples collected & 125 \\
\hline & \# sputum samples collected & 109 \\
\hline & \# Clinic Visits/subject & $5(1-8)$ \\
\hline & F508del/F508del & $20(56 \%)$ \\
\hline & F508del/other & $14(39 \%)$ \\
\hline & other/other & $2(5 \%)$ \\
\hline
\end{tabular}

Values are presented as number (\%) or median (range) of the 12 infants with the genotype F508del/other were pancreatic insufficient as confirmed by a pancreatic stool elastase $<200 \mathrm{mcg} / \mathrm{g}$ of stool. The adult CF cohort had a median age of 29.1 years, a median $\mathrm{FEV}_{1}$ of $56 \%$ predicted at baseline and all were confirmed pancreatic insufficient.

\section{CCSP, Desmosine and Cathepsin B concentrations in infants}

BALF CCSP concentration, plasma CCSP concentration and urinary desmosine concentration did not change significantly in CF infants during the 2 year study period (Additional file 1 shows cumulative biomarker concentrations). Urinary cathepsin B concentration was higher in CF infants than in healthy controls $(p=0.005$, Fig. 1$)$. The estimated ROC curve had an area under the curve of 0.85 (95\% CI: 0.79, 0.90) using urinary cathepsin B concentration to distinguish between CF and healthy infants (Fig. 2). There was a positive, significant association between CF infant plasma CCSP concentration with CF infant BALF CCSP concentration (Fig. 3, $p=0.046$ ). There was not a statistically significant association between CF urinary and BALF cathepsin B concentration. A positive, statistically significant association was detected between $\mathrm{CF}$ infant urinary cathepsin $\mathrm{B}$ concentration and urinary desmosine concentration ( $p=0.006$; Additional file 2).

\section{Comparison of CF infant biomarker concentrations with adult CF cohort}

CF infants had a BALF CCSP concentration that was significantly higher than that in adult CF sputum collected during an outpatient clinic visit $(p<0.001$, Fig. 4) [17]. CF infant BALF and urinary cathepsin B concentration was significantly lower than adult sputum and urinary cathepsin B concentration collected during an outpatient clinic visit $(p=0.002$ and $p=0.022$, respectively, Fig. 5).

\section{Correlations of targeted biomarker concentrations with lung function and markers of infection and inflammation in CF infants}

There was no significant association between \% neutrophils or absolute neutrophil count in BALF, BALF NE and CCSP, Cathepsin B or desmosine concentrations (Additional file 3). There was a positive, significant association between plasma CCSP concentration and the presence of $M$. catarrhalis $(p=0.012)$, S. pneumoniae $(p=0.037)$ and $S$. aureus $(p=0.020)$ in BALF culture. Additional file 4 shows the number of $\mathrm{CF}$ infants who were positive for each of the CF pathogens on standard culture. There was no association detected between targeted biomarker concentration and the presence of $P$. aeruginosa. CF infant BALF CCSP was negatively associated with BALF IL-8 concentration $(p=0.017)$. There was no correlation between CF infant 


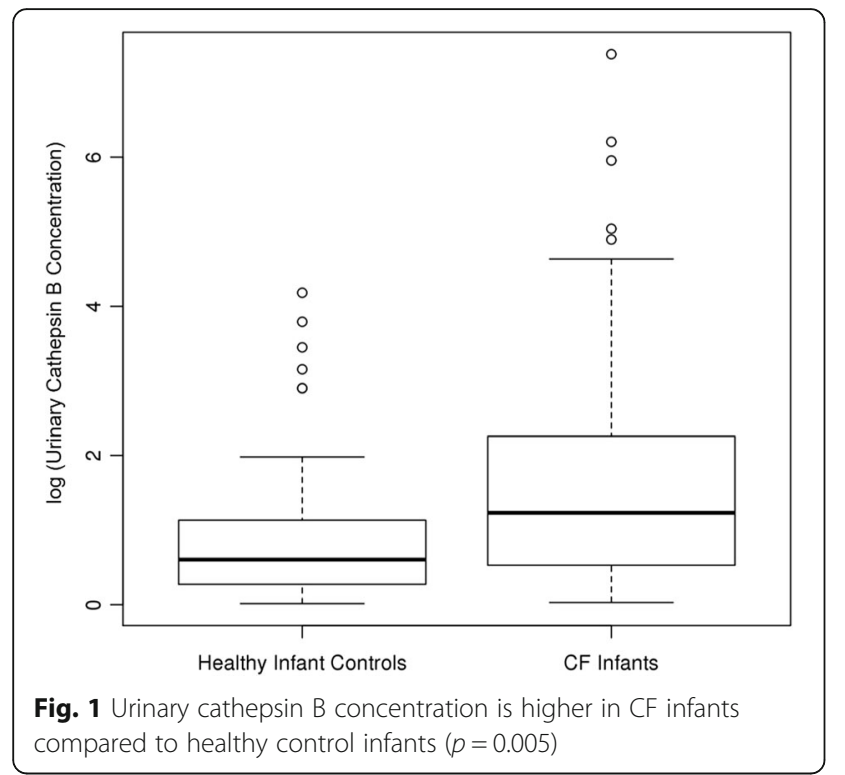

BALF biomarkers and the additional cytokines measured; however, cytokine concentrations in infant BALF are represented in Additional file 5. There was no correlation between targeted biomarker concentration and $\mathrm{FEV}_{0.5}$ (Additional file 6 shows the analysis of $\mathrm{FEV}_{0.5}$ and the targeted biomarkers).

\section{Discussion}

There is an unmet need in this population, with no objective means by which to identify and follow the progression of lung disease in CF infants. Through the comparison to healthy controls and older subjects with $\mathrm{CF}$,

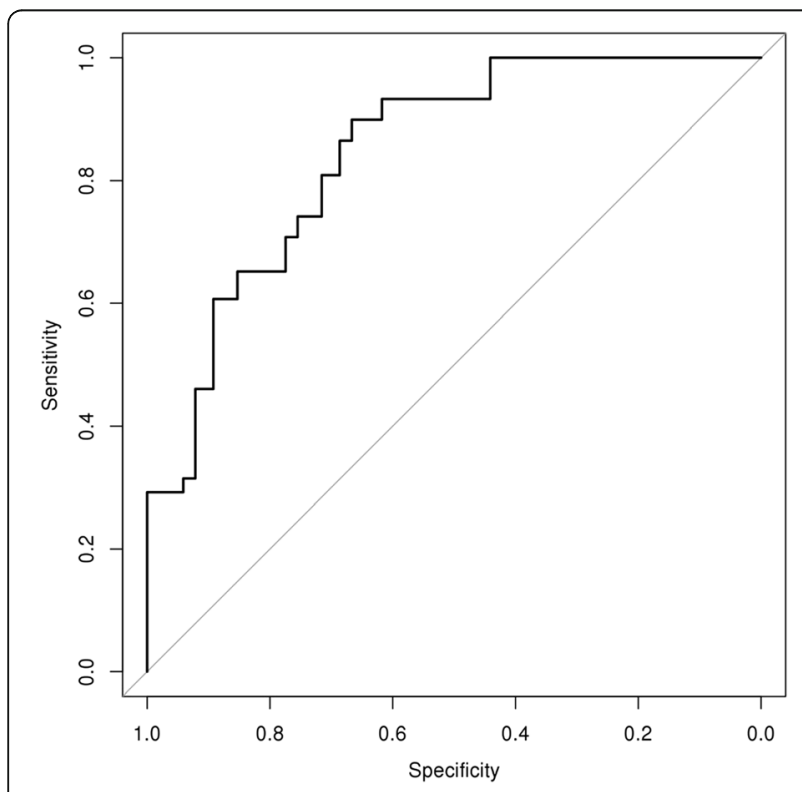

Fig. 2 ROC curve for the ability of urinary cathepsin B concentration to distinguish between CF and healthy, control infants

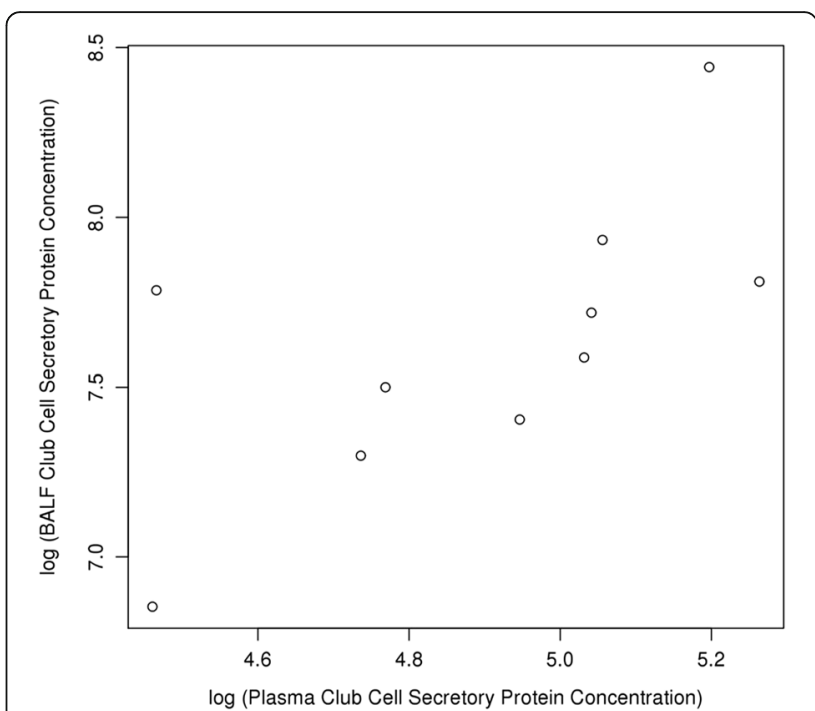

Fig. 3 A positive, significant association between CF infant plasma CCSP and concentration and CF infants BALF concentration was observed $(p=0.046)$

our findings suggest that CCSP and cathepsin B are potential biomarkers of lung disease activity in infants and should be investigated in future longitudinal and mechanistic studies.

The search for biomarkers of CF lung disease in infants and children remains challenging as they do not typically expectorate sputum, traditional lung function testing is not attainable, BALF is not routinely obtained, cumulative radiation exposure is a concern and phlebotomy can be difficult [35-38]. In addition to our prior work establishing a relationship between CCSP and desmosine concentration to CF pulmonary exacerbation in older CF patients, additional work in bronchial

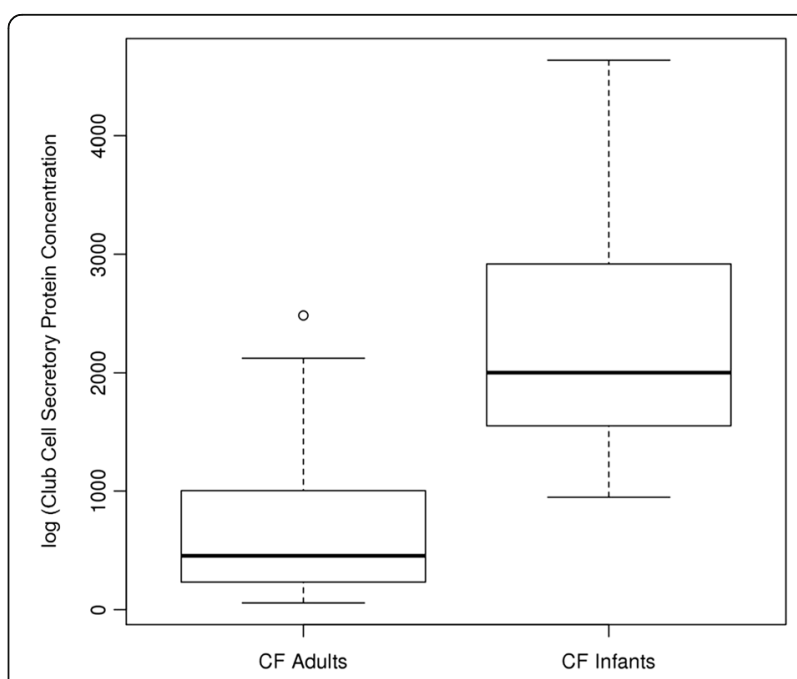

Fig. 4 CF infants had a significantly higher CCSP concentration measured in BALF compared to that in adult CF sputum $\left(p=3.868 \mathrm{e}^{-0.6}\right)$ 

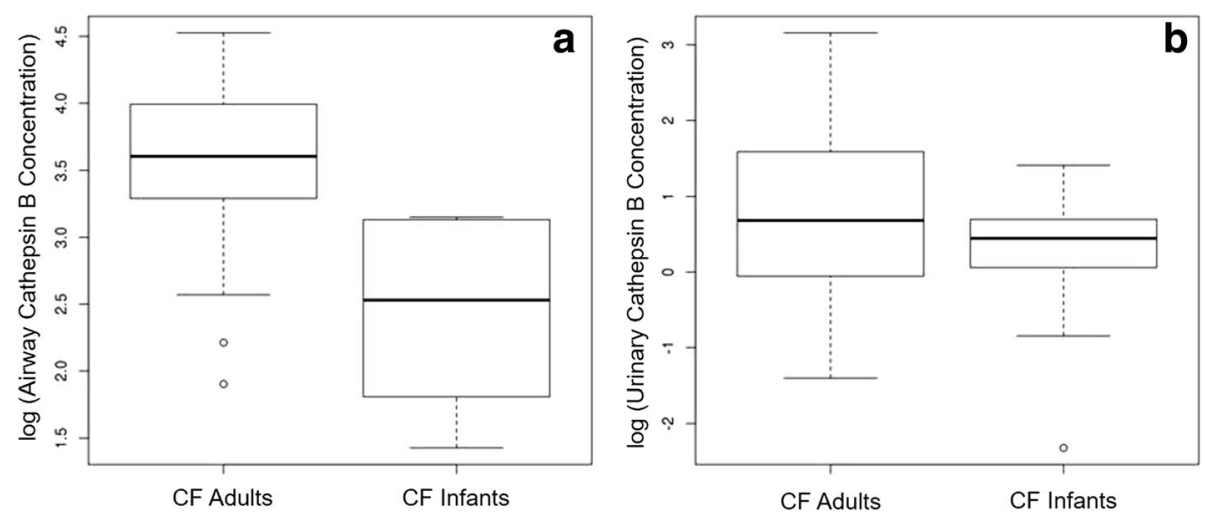

Fig. 5 a CF infant BALF cathepsin B concentration was significant lower than that in adult sputum $(p=0.002)$, and (b) CF infant urinary cathepsin B concentration was significantly lower than that in adult urine $(p=0.022)$

secretions in cell culture led us to investigate these three targeted biomarkers in a CF infant cohort [11, 12, 17, 18]. Utilizing quantitative proteomics to investigate the in vitro bronchial epithelial secretome, uteroglobinrelated protein 2 (i.e. CCSP) was found to be decreased and cathepsin B was increased in CF secretions compared to non-CF secretions [18]. These findings were in the absence of inflammatory cells and pathogens, suggesting altered immune and injury repair proteins related to CFTR dysfunction [18]. These three biomarkers have shown clinical and biological relevance in CF, providing a foundation for this investigation in infants.

Although we did not find that CCSP or desmosine concentration changed significantly over the first 2 years of life, we identified differences in cathepsin B concentration between our CF infants, healthy controls and older subjects with CF. We are the first to report the presence of cathepsin B in the urine and BALF of infants with CF. Although previous work has identified the presence of NE in CF infant BALF, ours is the first to document the presence of a cysteine protease in the $\mathrm{CF}$ infant airway [9]. Cathepsin B concentration was found to be increased in BALF from baboons who subsequently developed BPD, suggesting a role in the development of chronic lung disease [21]. CF infants had a significantly higher urinary cathepsin $\mathrm{B}$ concentration than normal, healthy infants without CF. Lung disease in $\mathrm{CF}$ is known to have its onset early in life and the higher concentration of cathepsin $\mathrm{B}$ is a potential indication of early airway damage. In addition, the CF infants had significantly lower concentrations of cathepsin B in their urine and BALF compared to an older cohort of subjects with CF who had more established lung disease. Only 5 of the 33 infants with CF in our study were infected with $P$. aeruginosa, and these subjects did not have a higher concentration of urinary or BALF cathepsin B, confirming a previous finding that cathepsins are not reliable markers of $P$. aeruginosa infection in CF [39]. Urinary cathepsin B concentration was positively associated with urinary desmosine concentration, confirming the presence of these two deleterious proteins in CF infants. An elevated urinary desmosine concentration in premature infants has been suggested as a biochemical marker of damage to the developing lung, and also has been shown to decrease during inpatient treatment for a CF pulmonary exacerbation in older patients [12, 22, 40]. Cathepsin $\mathrm{B}$ in the airway of subjects with CF is thought to be a marker of inflammation; however, our study was not designed to investigate mechanism of action.

CCSP concentration was significantly increased in infant BALF compared to our older subjects with CF. In addition, BALF CCSP concentration was negatively associated with IL-8 and positively correlated with blood CCSP concentration. Our previous longitudinal studies of sputum CCSP in $\mathrm{CF}$ have shown increased concentrations during times of stability compared to hospitalization for a CF pulmonary exacerbation [17]. CCSP has anti-inflammatory properties and is primarily produced by non-ciliated Club Cells in the conducting airways. Club cells secrete CCSP in very high concentrations in the epithelial lining fluid where it modulates the production and activity of phospholipase $\mathrm{A}_{2}$, interferon- $\gamma$ and tumor necrosis factor- $\alpha$, serving to protect the lung against oxidative stress [41-43]. Given that infants still have relatively healthy airways compared to adults with $\mathrm{CF}$, they may have a higher density of intact Club Cells in the airways, leading to a higher measureable concentration of CCSP. Interestingly, CCSP has been studied in premature infants in the context of the development of bronchopulmonary dysplasia (BPD). CCSP concentration in tracheal aspirates from premature infants increases with age and in response to infection [19, 44] . Airway CCSP concentration was lower and not inducible in those premature infants who developed BPD or died, compared to those infants who did not develop BPD [20]. Although we 
do not have airway CCSP concentration in healthy control infants for comparison, infants with CF may have a surge of CCSP during the first year of life as an antiinflammatory, anti-infectious response to the development of CF lung disease. The positive correlation between BALF and plasma CCSP concentration suggests that plasma levels may be a surrogate for airway CCSP concentration. Plasma CCSP concentration was also positively associated with bacteria not thought to be pathogenic in CF. Although the mechanistic role of CCSP in the development of CF lung disease is unclear, our findings suggest CF infants have significantly more of this biomarker detected in their airways and this was associated with less airway inflammation.

Our study is not without limitation. Our cohort of CF infants was small, and the subset who received a bronchoscopy with lavage had even more limited numbers. We compared biomarker concentration in two airway specimens (BALF and expectorated sputum) and in two CF populations (adults and children). Comparing the concentration of cellular and non-cellular components in BALF with sputum introduces a dilution factor; however, "normalization" of BALF for epithelial lining fluid (ELF) is not recommended due to a lack of a reliable method for its quantification [45]. Previous work in CF has determined that sputum may be a sample more highly concentrated in inflammatory mediators than BALF [46]. In our study, the CCSP concentration in BALF was significantly higher than sputum, and the difference in cathepsin B concentration between BALF and sputum was strengthened by a similar difference in urinary cathepsin B concentration. Although comparing an older CF cohort with CF infants may seem unorthodox, other validated biomarkers of CF lung disease reflect disease activity, regardless of age. Both sputum NE and IL-8 concentrations are negatively associated with lung function and are correlates of disease severity $[36,47]$. We anticipate that CCSP and cathepsin B concentrations may behave in a similar fashion. This study was not designed to elucidate the mechanisms of action of the three targeted biomarkers; instead, we identified differences in cohorts of $\mathrm{CF}$ and healthy subjects that can serve to generate hypotheses for further longitudinal and mechanistic studies. Finally, we measured cathepsin B using an ELISA and did not measure protease activity.

\section{Conclusions}

Our study is the first to measure CCSP and cathepsin B in infants with $\mathrm{CF}$ and compare these concentrations with those in control infants and older subjects with CF. We have identified CCSP and cathepsin B as potential biomarkers of CF lung disease and future studies are needed to better elucidate the mechanisms underlying their presence.

\section{Additional files}

Additional file 1: Cumulative data for targeted biomarkers in healthy control and CF infants. (PDF $49 \mathrm{~kb}$ )

Additional file 2: Plot of urinary cathepsin B concentration vs. urinary desmosine concentration. (JPEG $157 \mathrm{~kb}$ )

Additional file 3: Additional plots of inflammatory marker analysis. (JPEG $167 \mathrm{~kb}$ )

Additional file 4: Table summarizing the culture results for all CF infants. (PDF 34 kb)

Additional file 5: Additional plots of cytokine concentrations in CF infant BALF. (JPEG $134 \mathrm{~kb}$ )

Additional file 6: Plots summarizing the statistical analysis of $\mathrm{FEV}_{0.5}$ with targeted biomarkers. (JPEG $159 \mathrm{~kb}$ )

\section{Abbreviation}

BALF: Bronchoalveolar lavage fluid; BPD: Bronchopulmonary dysplasia; CCSP: Club cell secretory protein; CF: Cystic fibrosis; CFTR: Cystic fibrosis transmembrane conductance regulator; CV: Coefficient of variation; $\mathrm{FEV}_{0.5}$ : Forced expiratory volume in $0.5 \mathrm{~s}_{;} \mathrm{FEV}_{1}$ : Forced expiratory volume in 1 s; FVC: Forced vital capacity; HRCT: High-resolution computed tomography; IL-8: Interleukin-8; iPFT: Infant pulmonary function testing; IRB: Institutional review board; LCI: Lung clearance index; LOD: Limit of detection; NBS: Newborn screening; NE: Neutrophil elastase; NP: Nasopharyngeal; ROC: Receiver operator characteristic; RVRTC: Raised volume rapid thoracoabdominal technique; UMN: University of Minnesota

\section{Acknowledgements}

The authors wish to thank the adults with CF and the families of infants with and without cystic fibrosis who allowed their children to participate in this study. The authors did not receive any financial assistance to conduct this study or write this manuscript.

\section{Funding}

This work was supported by grants from the American Thoracic Society/ Cystic Fibrosis Foundation [ATS/CFF CF-08-001] and the National Institutes of Health [K12HD068322, UL1TR000114]. The ATS, CFF and NIH had no role in the design of the study and collection, analysis and interpretation of the data and in writing the manuscript.

\section{Availability of data and materials}

The datasets used and/or analyzed during this current study are available from the corresponding author on reasonable request.

\section{Authors' contributions}

TAL performed the literature search, participated in data collection, conceived of the study design, participated in the data analysis, prepared the first draft of the manuscript and edited the final manuscript; CBW participated in the data collection, and reviewed and edited the final manuscript; MGN participated in data collection, participated in data analysis and reviewed and edited the final manuscript; CWB participated in data collection, participated in data analysis and reviewed and edited the final manuscript; CEM participated in data collection, participated in data analysis and reviewed and edited the final manuscript; CSR participated in data analysis and reviewed and edited the final manuscript; CHW contributed to the study design, participated in data analysis and reviewed and edited the final manuscript. All authors read and approved the final manuscript.

Ethics approval and consent to participate

Ethics approval and consent was obtained from the University of Minnesota Institutional Review Board (IRB\#0809 M45601 and IRB\#0812 M55581).

Consent for publication

Not applicable

Competing interests

The authors declare they have no competing interests. 


\section{Publisher's Note}

Springer Nature remains neutral with regard to jurisdictional claims in published maps and institutional affiliations.

\begin{abstract}
Author details
'Minnesota CF Center, Department of Pediatrics, University of Minnesota Masonic Children's Hospital, 420 Delaware St. SE; MMC-742, Minneapolis, MN 55455, USA. ${ }^{2}$ School of Public Health, Division of Biostatistics, University of Minnesota, Minneapolis, MN, USA. ${ }^{3}$ Department of Medicine, Division of Pulmonary, Allergy, Critical Care and Sleep Medicine, University of Minnesota and Veterans Administration Medical Center, Minneapolis, MN, USA.
\end{abstract}

Received: 9 October 2017 Accepted: 29 December 2017 Published online: 08 January 2018

\section{References}

1. Pillarisetti N, Williamson E, Linnane B, Skoric B, Robertson CF, Robinson P, Massie J, Hall GL, Sly P, Stick S, Ranganathan S. Australian respiratory early surveillance team for cystic fibrosis (AREST CF): infection, inflammation, and lung function decline in infants with cystic fibrosis. Am J Respir Crit Care Med. 2011;184(1):75-81.

2. Mott LS, Park J, Gangell CL, de Klerk NH, Sly PD, Murray CP, Stick SM Australian respiratory early surveillance team for cystic fibrosis (AREST CF) study group: distribution of early structural lung changes due to cystic fibrosis detected with chest computed tomography. J Pediatr. 2013;

3. Welsh MJ, Ramsey BW, Accurso FJ, Cutting GR. Cystic fibrosis. In: Anonymous, editor. Cystic fibrosis in the metabolic and molecular basis of inherited disease, vol. 3. 7th ed. New York: McGraw-Hill; 2001. p. 521-88.

4. Mott LS, Park J, Murray CP, Gangell CL, de Klerk NH, Robinson PJ, Robertson CF, Ranganathan SC, Sly PD, Stick SM. AREST CF: progression of early structural lung disease in young children with cystic fibrosis assessed using CT. Thorax. 2012;67(6):509-16.

5. Sly PD, Brennan S, Gangell C, de Klerk N, Murray C, Mott L, Stick SM, Robinson PJ, Robertson CF, Ranganathan SC. Australian respiratory early surveillance team for cystic fibrosis (AREST-CF): lung disease at diagnosis in infants with cystic fibrosis detected by newborn screening. Am J Respir Crit Care Med. 2009;180(2):146-52.

6. Ramsey KA, Schultz A, Stick SM. Biomarkers in Paediatric cystic fibrosis lung disease. Paediatr Respir Rev. 2015:16(4):213-8.

7. Khan TZ, Wagener JS, Bost T, Martinez J, Accurso FJ, Riches DW. Early pulmonary inflammation in infants with cystic fibrosis. Am J Respir Crit Care Med. 1995;151(4):1075-82.

8. Stoltz DA, Meyerholz DK, Pezzulo AA, Ramachandran S, Rogan MP, Davis GJ, Hanfland RA, Wohlford-Lenane C, Dohrn CL, Bartlett JA, Nelson GA 4th, Chang EH, Taft PJ, Ludwig PS, Estin M, Hornick EE, Launspach JL, Samuel M, Rokhlina T, Karp PH, Ostedgaard LS, Uc A, Starner TD, Horswill AR, Brogden KA, Prather RS, Richter SS, Shilyansky J, McCray PB Jr, Zabner J, Welsh MJ. Cystic fibrosis pigs develop lung disease and exhibit defective bacterial eradication at birth. Sci Transl Med. 2010;2(29):29ra31.

9. Sly PD, Gangell CL, Chen L, Ware RS, Ranganathan S, Mott LS, Murray CP, Stick SM. AREST CF investigators: risk factors for bronchiectasis in children with cystic fibrosis. N Engl J Med. 2013;368(21):1963-70.

10. Rogan MP, Taggart CC, Greene CM, Murphy PG, O'Neill SJ, McElvaney NG. Loss of microbicidal activity and increased formation of biofilm due to decreased lactoferrin activity in patients with cystic fibrosis. J Infect Dis. 2004;190(7):1245-53.

11. Laguna TA, Wagner BD, Luckey HK, Mann SA, Sagel SD, Regelmann W, Accurso FJ. Sputum desmosine during hospital admission for pulmonary exacerbation in cystic fibrosis. Chest. 2009;136(6):1561-8.

12. Laguna TA, Wagner BD, Starcher B, Luckey Tarro HK, Mann SA, Sagel SD, Accurso FJ. Urinary desmosine: a biomarker of structural lung injury during CF pulmonary exacerbation. Pediatr Pulmonol. 2012;47(9):856-63.

13. Martin SL, Moffitt KL, McDowell A, Greenan C, Bright-Thomas RJ, Jones AM, Webb AK, Elborn JS. Association of airway cathepsin B and S with inflammation in cystic fibrosis. Pediatr Pulmonol. 2010:45(9):860-8.

14. Taggart CC, Lowe GJ, Greene CM, Mulgrew AT, O'Neill SJ, Levine RL, McElvaney NG. Cathepsin B, L, and S cleave and inactivate secretory leucoprotease einhibitor. J Biol Chem. 2001;276(36):33345-52.

15. Starosta V, Ratjen F, Rietschel E, Paul K, Griese M. Anti-inflammatory cytokines in cystic fibrosis lung disease. Eur Respir J. 2006;28(3):581-7.
16. Taggart CC, Greene CM, Smith SG, Levine RL, McCray PB Jr, O'Neill S, McElvaney NG. Inactivation of human beta-defensins 2 and 3 by elastolytic cathepsins. J Immunol. 2003;171(2):931-7.

17. Laguna TA, Williams CB, Brandy KR, Welchlin-Bradford C, Moen CE, Reilly CS, Wendt $\mathrm{CH}$. Sputum club cell protein concentration is associated with pulmonary exacerbation in cystic fibrosis. J Cyst Fibros. 2015;14(3):334-40.

18. Peters-Hall JR, Brown KJ, Pillai DK, Tomney A, Garvin LM, Wu X, Rose MC. Quantitative proteomics reveals an altered cystic fibrosis in vitro bronchial epithelial secretome. Am J Respir Cell Mol Biol. 2015;53(1):22-32.

19. Lassus P, Nevalainen TJ, Eskola JU, Andersson S. Clara-cell secretory protein in preterm infants' tracheal aspirates correlates with maturity and increases in infection. Pediatr Pulmonol. 2000;30(6):466-9.

20. Ramsay PL, DeMayo FJ, Hegemier SE, Wearden ME, Smith CV, Welty SE. Clara cell secretory protein oxidation and expression in premature infants who develop bronchopulmonary dysplasia. Am J Respir Crit Care Med. 2001;164(1):155-61.

21. Altiok O, Yasumatsu R, Bingol-Karakoc G, Riese RJ, Stahlman MT, Dwyer W, Pierce RA, Bromme D, Weber E, Cataltepe S. Imbalance between cysteine proteases and inhibitors in a baboon model of bronchopulmonary dysplasia. Am J Respir Crit Care Med. 2006;173(3):318-26.

22. Cherukupalli K, Larson JE, Puterman M, Sekhon HS, Thurlbeck WM. Comparative biochemistry of gestational and postnatal lung growth and development in the rat and human. Pediatr Pulmonol. 1997;24(1):12-21.

23. Laguna TA, Williams CB, Nunez MG, Williams CW, Reilly CS, Wendt CH. Biomarkers of early lung disease in infants with cystic fibrosis [abstract]. Pediatr Pulmonol Suppl. 2015;41:274.

24. Rosenstein BJ. Cutting, GR: the diagnosis of cystic fibrosis: a consensus statement. Cystic Fibrosis Foundation consensus panel. J Pediatr. 1998; 132(4):589-95

25. Stocks J, Godfrey S, Beardsmore C, Bar-Yishay E, Castile R. ERS/ATS task force on standards for infant respiratory function testing. European Respiratory Society/American Thoracic Society: Plethysmographic measurements of lung volume and airway resistance. ERS/ATS task force on standards for infant respiratory function testing. European Respiratory Society/ American Thoracic Society. Eur Respir J. 2001;17(2):302-12.

26. Castile R, Filbrun D, Flucke R, Franklin W, McCoy K. Adult-type pulmonary function tests in infants without respiratory disease. Pediatr Pulmonol. 2000; 30(3):215-27.

27. American Thoracic Society. European Respiratory Society: ATS/ERS statement: raised volume forced expirations in infants: guidelines for current practice. Am J Respir Crit Care Med. 2005;172(11):1463-71.

28. Saiman L, Siegel J. Cystic Fibrosis Foundation: infection control recommendations for patients with cystic fibrosis: microbiology, importan pathogens, and infection control practices to prevent patient-to-patient transmission. Infect Control Hosp Epidemiol. 2003:24(5 Suppl):S6-52.

29. Saiman L, Siegel JD, LiPuma JJ, Brown RF, Bryson EA, Chambers MJ, Downer VS, Fliege J, Hazle LA, Jain M, Marshall BC, O'Malley C, Pattee SR, Potter-Bynoe G, Reid S, Robinson KA, Sabadosa KA, Schmidt HJ, Tullis E, Webber J, Weber DJ. Cystic fibrous foundation, Society for Healthcare Epidemiology of America: infection prevention and control guideline for cystic fibrosis: 2013 update. Infect Control Hosp Epidemiol. 2014;35(Suppl 1):S1-S67.

30. Burns JL, Rolain JM. Culture-based diagnostic microbiology in cystic fibrosis: can we simplify the complexity? J Cyst Fibros. 2014;13(1):1-9.

31. Sagel SD, Kapsner R, Osberg I, Sontag MK, Accurso FJ. Airway inflammation in children with cystic fibrosis and healthy children assessed by sputum induction. Am J Respir Crit Care Med. 2001;164(8 Pt 1):1425-31.

32. Huang JT, Chaudhuri R, Albarbarawi O, Barton A, Grierson C, Rauchhaus P, Weir CJ, Messow M, Stevens N, McSharry C, Feuerstein G, Mukhopadhyay S, Brady J, Palmer CN, Miller D, Thomson NC. Clinical validity of plasma and urinary desmosine as biomarkers for chronic obstructive pulmonary disease. Thorax. 2012:67(6):502-8.

33. Wagner BD, Accurso FJ, Laguna TA. The applicability of urinary creatinine as a method of specimen normalization in the cystic fibrosis population. J Cyst Fibros. 2010;9(3):212-6.

34. R-Core Team: NIme: linear and nonlinear mixed effects models 2016.

35. Sagel SD, Chmiel JF, Konstan MW. Sputum biomarkers of inflammation in cystic fibrosis lung disease. Proc Am Thorac Soc. 2007:4(4):406-17.

36. Sagel SD, Wagner BD, Anthony MM, Emmett P, Zemanick ET. Sputum biomarkers of inflammation and lung function decline in children with cystic fibrosis. Am J Respir Crit Care Med. 2012;186(9):857-65. 
37. Sagel SD. Identifying novel endpoints for cystic fibrosis clinical trials. Adv Pediatr Infect Dis. 2005;52:115-27.

38. Sagel SD. Noninvasive biomarkers of airway inflammation in cystic fibrosis. Curr Opin Pulm Med. 2003;9(6):516-21.

39. Naudin C, Joulin-Giet A, Couetdic G, Plesiat P, Szymanska A, Gorna E, Gauthier F, Kasprzykowski F, Lecaille F, Lalmanach G. Human Cysteine Cathepsins are not reliable markers of infection by Pseudomonas Aeruginosa in cystic fibrosis. PLoS One. 2011;6(9):e25577.

40. Bruce MC, Poncz L, Klinger JD, Stern RC, Tomashefski JF Jr, Dearborn DG Biochemical and pathologic evidence for proteolytic destruction of lung connective tissue in cystic fibrosis. Am Rev Respir Dis. 1985;132(3):529-35.

41. Levin SW, Butler JD, Schumacher UK, Wightman PD, Mukherjee AB. Uteroglobin inhibits phospholipase A2 activity. Life Sci. 1986;38(20):1813-9.

42. Mantile G, Miele L, Cordella-Miele E, Singh G, Katyal SL, Mukherjee AB. Human Clara cell 10-kDa protein is the counterpart of rabbit uteroglobin. J Biol Chem. 1993;268(27):20343-51.

43. Dierynck I, Bernard A, Roels H, De Ley M. The human Clara cell protein: biochemical and biological characterisation of a natural immunosuppressor. Mult Scler. 1996;1(6):385-7.

44. Loughran-Fowlds AS, Lin JW, Oei J, Michalowski J, Henry R, Lui K. Early postnatal surge of serum Clara cell secretory protein in newborn infants. Neonatology. 2012;101(2):125-31.

45. de Blic J, Midulla F, Barbato A, Clement A, Dab I, Eber E, Green C, Grigg J, Kotecha S, Kurland G, Pohunek P, Ratjen F, Rossi G. Bronchoalveolar lavage in children. ERS task force on bronchoalveolar lavage in children. European Respiratory Society. Eur Respir J. 2000;15(1):217-31.

46. McGarvey LP, Dunbar K, Martin SL, Brown V, Macmahon J, Ennis M, Elborn JS. Cytokine concentrations and neutrophil elastase activity in bronchoalveolar lavage and induced sputum from patients with cystic fibrosis, mild asthma and healthy volunteers. J Cyst Fibros. 2002; (4):269-75.

47. Mayer-Hamblett N, Aitken ML, Accurso FJ, Kronmal RA, Konstan MW, Burns JL, Sagel SD, Ramsey BW. Association between pulmonary function and sputum biomarkers in cystic fibrosis. Am J Respir Crit Care Med. 2007;175(8):822-8.

\section{Submit your next manuscript to BioMed Central and we will help you at every step:}

- We accept pre-submission inquiries

- Our selector tool helps you to find the most relevant journal

- We provide round the clock customer support

- Convenient online submission

- Thorough peer review

- Inclusion in PubMed and all major indexing services

- Maximum visibility for your research

Submit your manuscript at www.biomedcentral.com/submit

) Biomed Central 